\title{
Physical literacy on the global agenda
}

\author{
Yao Ydo ${ }^{1}$
}

Accepted: 24 November 2020 / Published online: 6 January 2021

(C) UNESCO IBE 2021

Literacy is a complex concept, which continues to be interpreted and defined in multiple ways. The United Nations Resolution 56/116 (UN 2002) acknowledges the place of literacy at the heart of lifelong learning. It also acknowledges its fundamental role for the attainment of essential skills that enable people of all ages to address the challenges they may face in life. Furthermore, literacy represents one of the essential steps in basic education - an indispensable means for effective participation in the societies and economies of the twenty-first century.

The IBE has kept emphasizing the need for new forms of literacy (UNESCO IBE 2017). These relate particularly to new technologies such as digital literacy, information literacy, mass-media literacy, and social-media literacy, which are increasingly taken into account in the curriculum.

For this reason, I am pleased to introduce this special issue, which signals the IBE's strong interest in physical literacy, a concept that is beginning to shape learning theory and the global educational discourse.

The concept of physical literacy recognizes that humans learn for different reasons, whether for survival, social connection, or self-actualization. Learning to move could even be considered the first literacy we truly need to acquire as humans - at least well before we need to learn to read, write, comprehend, and calculate. If so, the importance of physical literacy becomes self-evident.

Learning to move one's body for social, aesthetic, competitive, and even survival reasons is linked not only to our health but also to the meaning and pleasure we gain from our everyday lives. Physical literacy is a concept that asks educators to celebrate each individual's strengths and to use these as a foundation for learning (and teaching) to live meaningful and healthy lives through physical activity, sport, recreation, and leisure.

Research on learning the necessary skills and attributes to live an active life provides insight that can be incorporated into how educators plan and execute appropriate

Yao Ydo

ibe.prospects@unesco.org

1 UNESCO International Bureau of Education, P.O. Box 199, 1211 Geneva 20, Switzerland 
pedagogical and instructional interventions pertaining to physical literacy development (Dudley et al. 2016; Cairney et al. 2019). Educators can make a number of organizational decisions and develop content in ways that help students learn new and increasingly complex movement sequences. If being physically literate is a goal of curriculum and sporting interventions, students need to learn a host of cognitive, social, affective, and physical skills, so they can use these outside formal educational institutions.

The aspirational goal of achieving a physically literate population begins with rethinking and applying good learning design in school and out-of-school movement experiences. Using UNESCO's (2015b) Quality Physical Education: Guidelines for Policy-Makers, UNESCO and partners are currently supporting four countries (Fiji, Mexico, South Africa, and Zambia) to develop inclusive, child-centered school policies and processes driven by physical literacy. These revised policies promote physical literacy and values-based learning as part of rounded development and global education priorities such as the SDG 4.

Physical literacy is the foundation of physical education, sport, and public health agendas. It is not a program, but the process considerations and aspirational outcomes of structured physical education provision, which are achieved more readily if learners encounter a range of age- and stage-appropriate opportunities. Quality physical education driven by physical literacy should expose and teach children and young people a wide variety of meaningful and inclusive movement experiences from the early years through their entire school journey to secondary-school education. Considering the importance of physical literacy for holistic human development, policy makers should place emphasis on this. They can make meaningful in-roads by constructing policy that supports physical literacy development from early years' education programs onwards. This includes encouraging active play every day and ensuring that children of all abilities will never be excluded from a movement learning experience. In terms of curricular and co-curricular programs, the promotion of physical literacy should then remain a key feature throughout primary and secondary education.

Furthermore, the International Charter for Physical Education, Physical Activity, and Sport (UNESCO 2015a) specifies that the education sector is not solely responsible for creating physically literate populations. Health and sport agencies must collaborate with education in creating a strategic vision that enables the fundamental right for all people to participate in meaningful physical activity across their life course.

Cornish et al. (2020) recently noted that, while education had progressed the concept of physical literacy extensively in recent times, applying this concept to the context of health is not well established. As physical literacy seeks to pursue and contribute solutions to multiple SDGs, the nature and direction of the relationship between physical literacy, physical activity, sporting participation, and health require further exploration with consideration of the theoretical underpinnings of physical literacy as a holistic concept.

In the future, both developed and developing countries will need to make progress on interdisciplinary policy making around physical literacy (Dudley et al. 2017). This has been, and will be, no small feat. There have been some notable achievements, as there is an abundance of public policy literature advocating for greater interdisciplinary collaboration (Holmes 2011). However, genuine engagement in the co-production of physical literacy policies will require changes in the culture and operations of health, sport, and education agencies. It will demand new competences and expectations of public servants as enablers. It will also ask and demand that education, sport, and health agencies have a clear orientation toward a public good and a readiness to actively engage with each other. 
I am pleased to introduce this special issue of Prospects, which brings together both conceptual and applied studies from around the globe in the common pursuit of creating a world of more engaged, thoughtful, and active citizens.

\section{References}

Cairney, J., Dudley, D., Kwan, M., Bulten, R., \& Kriellaars, D. (2019). Physical literacy, physical activity and health: Toward an evidence-informed conceptual model. Sports Medicine, 49(3), 371-383.

Cornish, K., Fox, G., Fyfe, T., Koopmans, E., Pousette, A., \& Pelletier, C. (2020). Understanding physical literacy in the context of health: A rapid scoping review. BMC Public Health, 20(1569), 1-19.

Dudley, D., Cairney, J., Wainwright, N., Kriellaars, D., \& Mitchell, D. (2017). Critical considerations for physical literacy policy in public health, recreation, sport, and education agencies. Quest, 69(4), 436-452.

Dudley, D., Goodyear, V., \& Baxter, D. (2016). Quality and health-optimizing physical education: Using assessment at the health and education nexus. Journal of Teaching in Physical Education, 35(4), 324-336.

Holmes, B. (2011). Citizens' engagement in policymaking and the design of public services. Department of Parliamentary Services Research Papers, vol. 1, pp. 1-64.

UNESCO (2015a). International charter of physical education, physical and sport. Paris: UNESCO. https:// unesdoc.unesco.org/ark:/48223/pf0000235409.

UNESCO (2015b). Quality physical education: Guidelines for policy-makers. Paris: UNESCO.

UNESCO IBE (2017). Future competences and the future of curriculum: A global reference for curricula transformation (M. Marope, P. Griffin, C. Gallagher, Authors). Geneva: UNESCO IBE.

United Nations (2002). Resolution 56/116 on United Nations literacy decade: Education for all. New York, NY: United Nations. https://undocs.org/pdf?symbol=en/A/RES/56/116.

Publisher's Note Springer Nature remains neutral with regard to jurisdictional claims in published maps and institutional affiliations. 